\title{
Optimal selection of Wind Turbine Generators
}

\author{
M. Bencherif \\ Renewable energy laboratory, \\ department of physics \\ University of Tlemcen, \\ B.P. 119, Tlemcen, Algeria
}

\author{
B.N.Brahmi \\ Renewable energy laboratory, \\ department of physics \\ University of Tlemcen, \\ B.P. 119 , Tlemcen, Algeria
}

\author{
A.Chikhaoui \\ Renewable energy laboratory, \\ department of physics \\ University of Tlemcen, \\ B.P. 119, Tlemcen, Algeria
}

\begin{abstract}
This paper examines optimum selection of wind turbines between site and wind turbine generators. An analysis methodology is done at the planning and development stages of installation of wind power stations will enable the wind power developer or the power utilities to make a judicious and rapid choice of suitable wind energy conversion system from the available potential sites. The methodology of analysis is based on the computations of annual capacity factors, which are done using the Weibull distribution function and power curve model. The methodology helps to the determination of the speeds characteristic range of the wind machines and to make easy the choice of the suitable wind turbine for a given site, in order to maximize the delivered energy for a given amount of available wind energy. This methodology is applied to install a wind energy conversion system at four sites in Algeria.
\end{abstract}

\section{Keywords}

Probability density function; power curve law; capacity factors; wind turbine generators; optimum siting; energy output.

\section{INTRODUCTION}

To describe the available wind distribution at a site and analyze the energy exchange between the wind and a Wind Energy Conversion System (WECS), Several Academic attempts regarding the evaluation of wind energy potential for different regions by using various probability distribution functions have been carried out by some researchers. Most of the researches have indicated Weibull distribution function [1], [2] and Rayleigh distribution function [3], [4] are the most commonly adopted methods to represent wind-speed distributions of various wind farms. Weibull distribution that uses scale parameter and shape parameter to express annual mean wind speed and associated standard deviation may appropriately represent the probability distribution of wind speeds. Since the mean wind speed can always be computed easily, all statistic parameters of Rayleigh density function are immediately available without massive additional computations. [5] Used two kinds of the Weibull distributions to analyze wind potential energy of two windy sites located in the coastal region of Red Sea. Eritrea. $\mathrm{Li}$ [6] and $\mathrm{Lu}$ et al. [7] conducted mathematical investigations using the two-parameter Weibull wind speed distribution to examine wind power potential and wind turbine characteristics in Hong Kong. Mathew et al. [8] presented an analytical approach to study the wind energy density, energy available in the wind spectra, and the energy received by turbine by using the Rayleigh wind speed distribution. Corotis et al. [9] preferred the Rayleigh distribution for the wind data. Other authors [10-12] also used the Weibull model and found that the wind data can be represented by the Weibull distribution. This type of approach relies on the appropriate use of the probability density function of wind speed. The parameters of the probability density function are usually determined based on the wind distribution statistics calculated from the measured hourly time-series data. On the other hand, WECS can operate at maximum efficiency only if it is designed for the site where it is to be set up, as rated power, cut-in, rated and cut-out wind speeds would be defined according to the site. These parameters can be chosen so as to maximize the delivered energy for a given amount of available wind energy. However, it is rather expensive to design a WECS for one site, so usually one chooses for a given site the best among existing machines. It is possible, nonetheless, to investigate the potentiality of a site in relation to a wind machine by means numerous criteria have been proposed for the pairing procedure since 1979 [13], and all of them basically bear the similar form of the combination of a statistical model of wind speed distribution and a power curve model of a WECS. Although this is the only procedure one can follow, the results are not always reliable due to the lack of consideration of the degree of approximation [14]. If a wind speed probability distribution and a turbine power (performance) curve are known, energy output from WECS can be obtained. Stevens and Smulders [15] matched the Weibull distribution with some power-law models of the WECS. However, Pallabazzer [14] pointed out that the energy output could be maximized by matching the actual wind frequency distribution of the site with a suitable model of the WECS. The above studies either investigated wind characteristics (wind speed and wind energy density) only, or focused on part of wind turbine characteristics of a given wind turbine generator such as the capacity factor, site efficiency which is defined as the ratio between the output energy and the maximum available energy converted by WECS running at constant design efficiency and the wind turbine efficiency of a chosen wind turbine and the availability factor. Once that the details of the wind resource is known of a site, the effective design of a wind power system of requires optimal pairing with the wind potential available on the site etc. The aim of this paper is to suggest a simple methodology for selecting the wind energy conversion system among existing ones, which can be installed at a desired site. This method is based on the pairing performance factor (Capacity Factor CF) for estimation of the average power output of the pairing between arbitrary sites and wind turbines. Instead of dealing with tedious bar-chart data of wind distribution and power curves, statistical approximation could easily describe them with several parameters, from which enormous time and storage resource can be saved. This is especially useful when cross-matching between a large number of sites and turbines, or when optimizing the configuration of turbine installation sites on wind farms. 


\section{THEORIES}

Before the installation of any wind turbine, it is necessary to estimate the expected power output in order to assess the economic viability of the project, usually based on wind statistics measured over a period of at least 1 year [2]. It has been concluded by Garcia et al. that the two-parameter Weibull probability model fits the real wind data better than the lognormal, gamma and Rayleigh models $[3,5,6]$. In other words, most wind speed distribution characteristics at any site can be described by two parameters: the shape parameter k, and the scale parameter $\mathrm{C}$. The fraction of time duration that the wind blows at speed $\mathrm{V}$ is thus determined by:

$$
f(V)=\frac{k}{C}\left(\frac{V}{C}\right)^{k-1} \exp \left(-\left(\frac{V}{C}\right)^{k}\right)
$$

Moreover, the cumulative density function of the Weibull distribution is defined as:

$$
F(V)=1-\exp \left(\left(\frac{V}{C}\right)^{k}\right)
$$

The kinetic energy in wind could never be completely converted into mechanical-rotation energy of any real wind machine, this is demonstrated by Betz (Betz limit), an ideal wind turbine can convert only 59\% of the available wind energy into site. The performance of wind turbine is described by its typical power curve. The power curve determines the functioning type of wind turbine. The actual wind power output from the wind turbine increases between cut-in and rated speed, and between rated and cut-out speed depend of system control device. As for the power curve model of a wind turbine, it can be modeled by four spec parameters: the cut-in speed Vc, the rated speed $\mathrm{Vr}$, the cut-out speed Vout, and the rated power $\operatorname{Pr}[14,15]$. The power curve of a wind turbine can be well approximated with the developed parabolic law, which is well described by the following expression:

$$
P(V)=\left\{\begin{array}{cl}
\frac{P r\left(a V^{2}+b V+C\right)}{(V r-V c)^{2}} & V c \leq V \leq V r \\
\operatorname{Pr} \quad & V r \leq V \leq \text { Vout } \\
0 & V>V \text { out }
\end{array}\right.
$$

This approximation works well for pitch-controlled turbines, but for stall-controlled turbines, it might fail to fit when $\mathrm{V}$ is large. However, this could be compensated by adjusting Vout to account for the discrepancy. It suitable to simulate the power curve of a pitch-controlled wind turbine and to a lesser extent a stall- or a yaw-controlled wind turbine, which do not have a constant power range and thus neglects the power output exceeding rated power Pr.

The constants $\mathrm{a}, \mathrm{b}$ and $\mathrm{C}$ are related to speeds characteristic of the machine by the following relations: Curve fitting Parameters

$\alpha=\frac{V r(V r+2 V c)}{(-0.08 V c-0.05 V r+\beta)\left(V r^{2}-V c^{2}\right)}$

The constants $\mathrm{a}, \mathrm{b}$ and $\mathrm{E}$

$$
2<\beta<4
$$

$$
\begin{gathered}
a=2(1-\alpha) \quad b=(1-a) V r-(a+1) V c \\
C=(V c-(1-a) V r) V c
\end{gathered}
$$
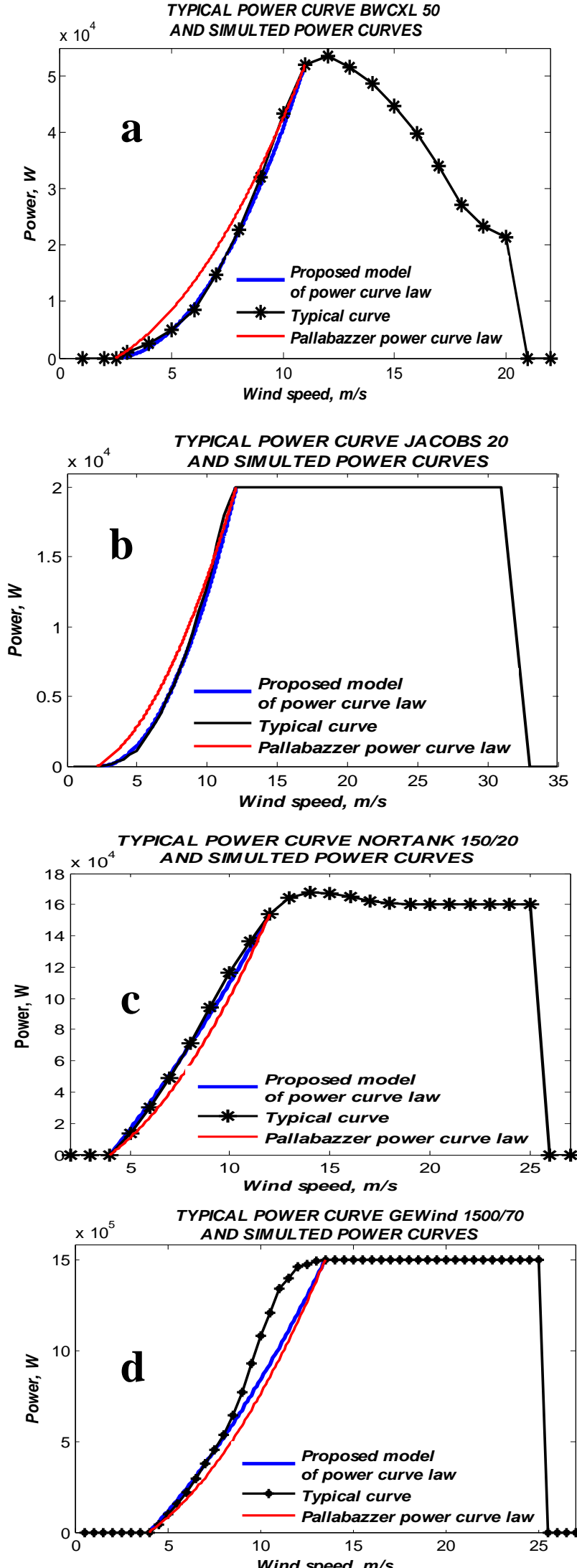

Figs 1: Comparison between typical curve and simulated curve 
Figures.1 depict the simulated curves using the fitting parameter $\beta$ examined to the typical curve of different wind turbines of various control system between cut-in and rated speed, the simulated curves in Figures.1 (a)-(b) are practically similar to the typical curves of the medium wind turbine BWCXL50 equipped with stall control and Jacobs 20 endowed with pitch control system. Figures.1 (c)-(d) show the typical curve of Nordtank 150/24 of wind turbine where the simulated curve is pretty analogue to the typical curve with a slight difference and the typical and simulated curve of a big size GE $1500 / 70$ wind turbine. The proposed model of power curve law is suitable better to approximate the typical power curve than other quadratic power curve models.

If the manufacturer's power curve data are not available, the parameter $\beta$ takes the value $3.09 \mathrm{~m} / \mathrm{s}$. This value is appropriate to much better simulate the powers curves of wind turbines with the suggested quadratic model, Figures.2 (a)-(d) show the simulated curves using $\beta=3.09$ compared to the usually used Pallabazzer quadratic power law model. These figures indicate that the proposed quadratic power law delivers a good approach to the typical power curves law.
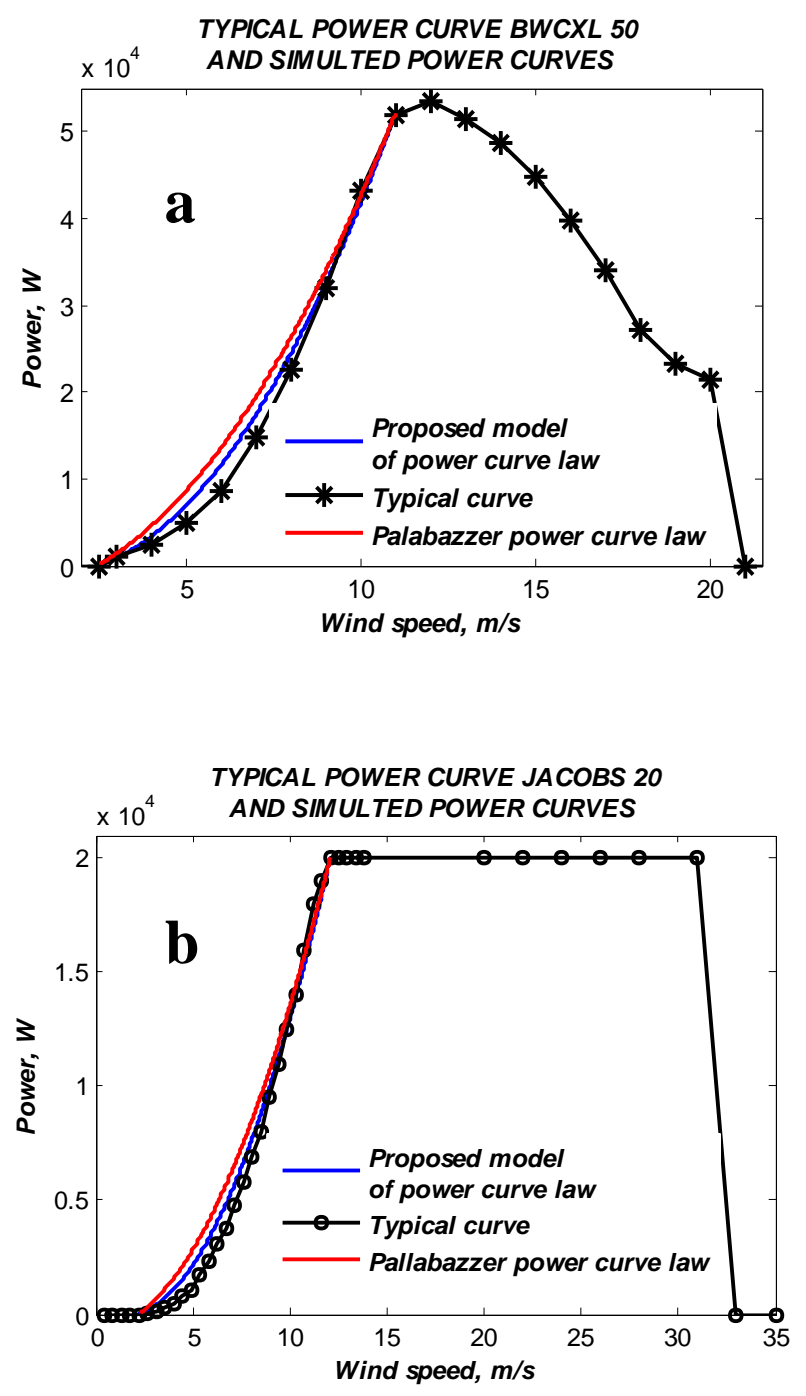
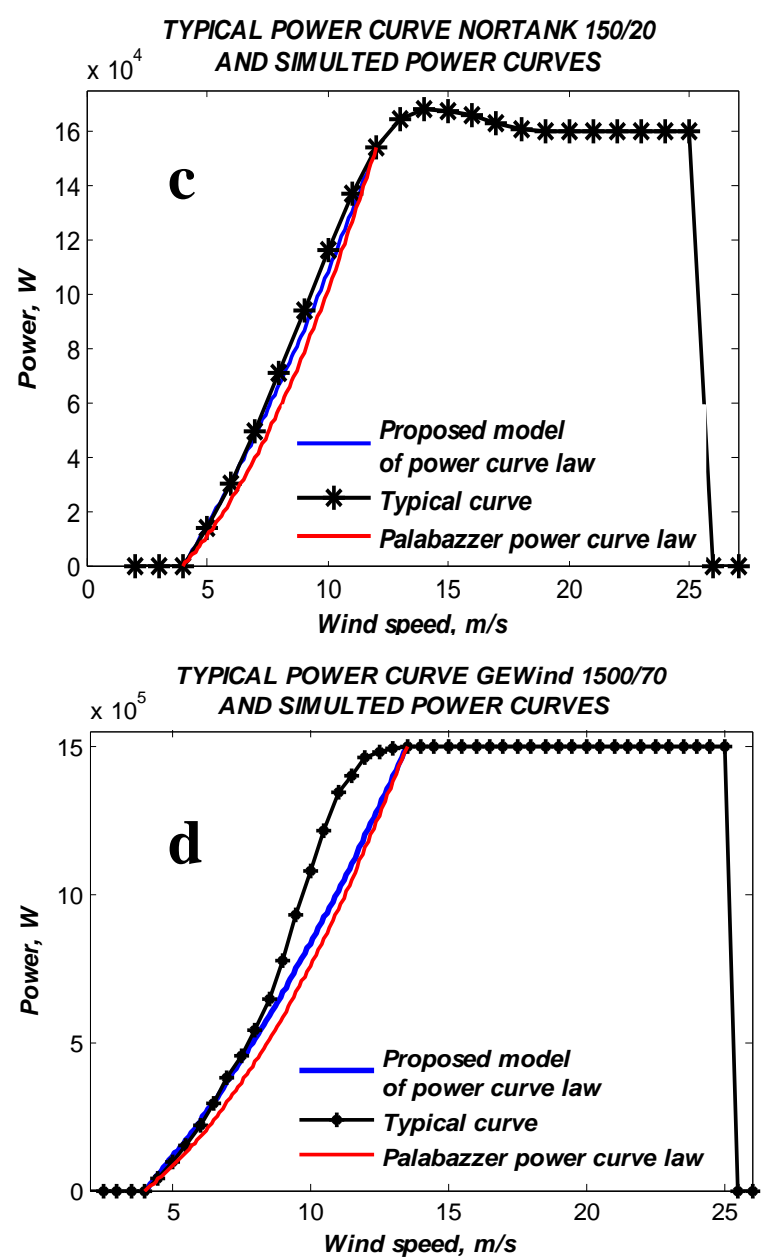

Figs 2: Comparison between typical curve and simulated curve with $\beta=3.09 \mathrm{~m} / \mathrm{s}$

\section{WIND TURBINE ENERGY OUTPUT AND CAPACITY FACTOR}

A wind energy conversion system can operate at its maximum efficiency only if it is designed for a particular site because the rated power and cut-in and cut-out wind speeds must be defined based on the site wind potentialities [16]. It is essential that these parameters are selected so that energy output from the wind energy conversion system is maximized. The performance of a wind turbine installed in a given site can be examined by the amount of mean power output over a period. The capacity factor $\mathrm{CF}$ is defined as the ratio of the mean power output to the rated electrical power $(\operatorname{Pr})$ of the wind turbine $[16,17,18,19$, $20]$. The mean energy output $E$ and capacity factor $C F$ of a wind turbine can be estimated using the following expressions based on Weibull distribution function $[16,17,18,19]$ :

$$
E=P_{\text {avearage }} T=T \int_{V c}^{V o u t} P(V) f(V) d V
$$

The average electrical energy output can be calculated by integrating Eq. (6) over the given intervals. Therefore, the energy output can be given as:

$$
E=T\left[\int_{V c}^{V r} P(V) f(V) d V+P r \int_{V r}^{V o u t} f(V) d V\right]
$$


The dimensionless capacity factor or so CF called mean power coefficient is defined as the index of wind turbine-site pairing performance. It compares the real production of the wind turbine for a given duration with the maximum production for this same duration, is denoted as $\mathrm{CF}$ :

$$
\begin{aligned}
& C F=\frac{E}{P r T}=\frac{\left[\int_{V c}^{V r} P(V) f(V) d V+\operatorname{Pr} \int_{V r}^{V o u t} f(V) d V\right]}{P r} \\
& C F=\frac{\int_{V c}^{V r} P(V) f(V) d V}{\operatorname{Pr}}+\operatorname{Pr} \int_{V r}^{V o u t} f(V) d V
\end{aligned}
$$

Although, Equation (10) can be further solved by introducing the incomplete gamma functions to yield a much simpler form. Since the incomplete gamma function curves usually bear similar characteristics with cubic polynomial curves in relevant cases, for this reason, the first integral of Eq. (9) can be approximated with a cubic polynomial, which can be easily calculated by any typical numerical integration techniques such as Gauss quadrature, six-point Gauss-Legendre quadrature or Simpson's rule. Herein the Simpson's three-eighths rule is used:

$$
\begin{aligned}
C F=-G(\text { Vout }) & +\frac{1}{8}[(1-a) G(V c)+(1+a) G(V r) \\
& +(3+a) G\left(\frac{V c+2 V r}{3}\right) \\
& \left.+(3-a) G\left(\frac{2 V c+V r}{3}\right)\right]
\end{aligned}
$$

Where

$$
G(V)=\exp \left(-\left(\frac{V}{C}\right)^{k}\right)
$$

For some cases, G (Vout) can be ignored when most of the wind speeds range below Vout. That is, when the wind turbine has a relatively higher Vout or the wind regime at the site has a relatively higher k. For such special cases, Eq. (10) can be simplified as:

$$
\begin{aligned}
C F=\frac{1}{8}[(1-a) & G(V c)+(1+a) G(V r) \\
& +(3+a) G\left(\frac{V c+2 V r}{3}\right) \\
& \left.+(3-a) G\left(\frac{2 V c+V r}{3}\right)\right]
\end{aligned}
$$

It should be noticed that in Eqs. (10), and (11), CF is independent of $\mathrm{Pr}$, depends only on speeds characteristic of the machine, i.e., cut-in speed Vc, rated speed Vr and cut-out speed Vout (Eqs. (10)); and the parameters of Weibull distribution function characterizing the site potentialities. Therefore, two wind turbines with the same $\mathrm{Vc}, \mathrm{Vr}$ and Vout but different rated power Pr get the same pairing performance at the same site. This is reasonable for performance-oriented cases because the turbine with larger nominal power is equivalent to the combination of several smaller turbines. The capacity factor reflects how effectively the turbine could harness the energy available in the wind spectra. Hence, $\mathrm{CF}$ is a function of the turbine as well as the wind regime characteristics. Usually the capacity factor is expressed on an annual basis. Capacity factor for a reasonably efficient turbine at a potential site may range from 0.25 to 0.4 . A capacity factor of 0.4 or higher indicates that the system is interacting with the regime very efficiently.

\section{PAIRING THE WIND TURBINE WITH WIND REGIME}

The performance of a wind energy conversion system at a given site depends heavily on the efficiency with which the turbine interacts with the wind regime. Therefore, it is indispensable that the speeds characteristics of the wind turbine and the wind regime at which it operates should be suitably matched. The capacity factor of the system can be a useful indication for the effective pairing of wind turbine and wind regime. For turbines with the same rotor size, rated power and conversion efficiency, the capacity factor is influenced by the availability of the turbine to the prevailing wind. In other words, the functional velocities of the turbine $(\mathrm{Vc}, \mathrm{Vr}$ and Vout) should be chosen in such a way that, the energy available with the wind regime is extracted to its maximum level. This in turn would require that the turbines should be individually designed for each site so that these functional parameters can be defined according to the site characteristics. This is not practical. Several wind turbines of different ratings and operational velocities are available in the market. A wind energy project planner can choose a system, best suited for his site, from these available options. Hence, it is important to identify the effect of these functional velocities that is $\mathrm{Vc}, \mathrm{Vr}$ and Vout on the turbine performance at the given location and ensure that the turbine and the wind regime are working in harmony.
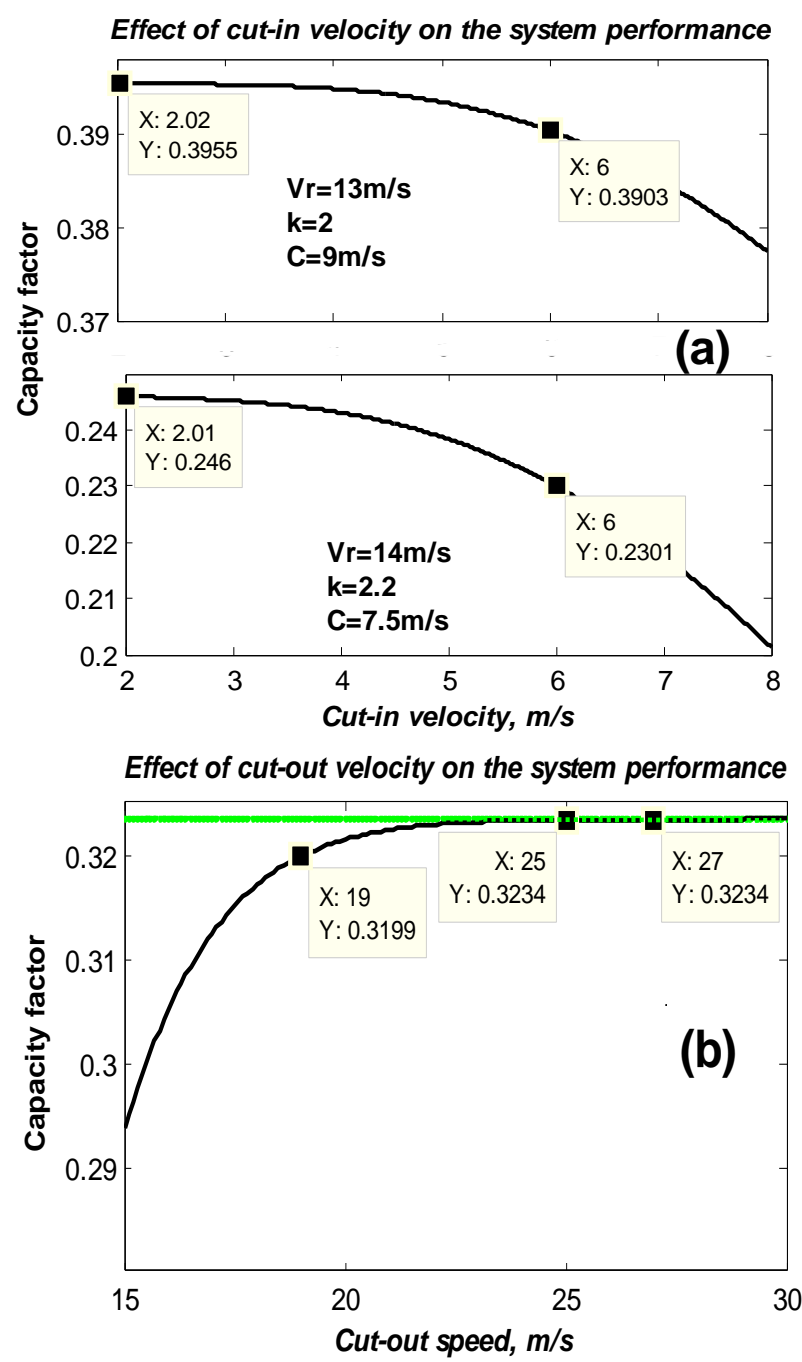
Effect of rated velocity on the system performance

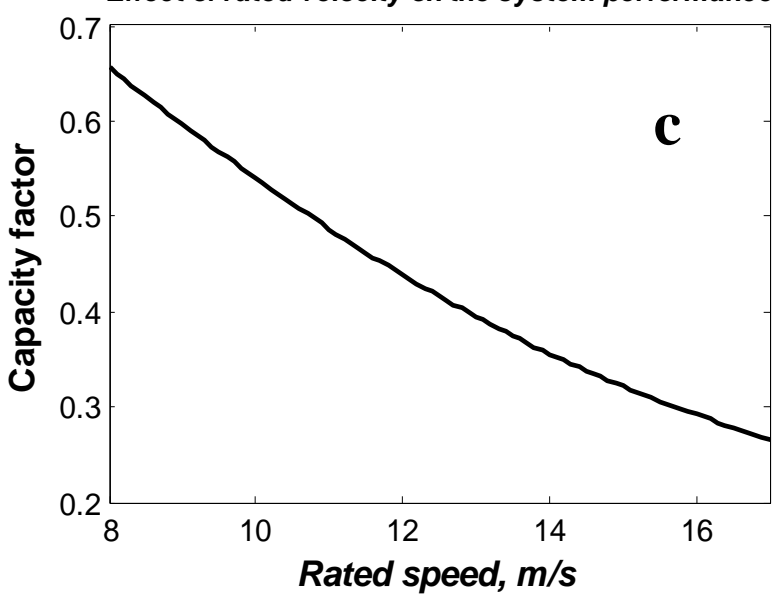

In order to identify the effect of cut-in velocity, compute the capacity factors of the turbine by varying Vc at different levels. Vout is kept at a reasonably higher value of $25 \mathrm{~m} / \mathrm{s}$. The capacity factors thus obtained are plotted against the respective cut-in speeds in Figure 3 (a). Up to a velocity of $2.0 \mathrm{~m} / \mathrm{s}$, Figure 3 (a) shows; the cut-in speed has a weak influence on the capacity factor, its effect does not exceed $10 \%$. However, for cut-in velocities higher than $2.0 \mathrm{~m} / \mathrm{s}$, there is a noticeable decrease in the capacity factor. Similar procedure may be followed for identifying optimum Vout of the turbine. In this case, $V_{c}$ is fixed and Vout is varied. Results are shown in Figure 3 (b). Effect of Vout on the system performance is prominent up to $15 \mathrm{~m} / \mathrm{s}$. With further increase in the cut-out velocity, the capacity factor is not improved considerably, while generally the commercial wind turbines own a cut-out speeds more than $20 \mathrm{~m} / \mathrm{s}$, in majority $25 \mathrm{~m} / \mathrm{s}$, its effect is insignificant on the pairing index CF, Figure.3 (b) show the limit effect of cut-out speed, which is described with Eq.(11). In the previous procedure, we have identified the effect of $\mathrm{Vc}$ and Vout based on the Weibull parameters $\mathrm{k}$ and $\mathrm{C}$, i.e., on the site characteristics. However, the machine characteristics also have to be considered while choosing $\mathrm{Vc}$ and Vout for a system. The cut-in speed should be strong enough to overcome all the system losses. Similarly, capability of the system in sustaining extreme aerodynamic loads should be considered while fixing up Vout.

Comparison of power curves for different rated wind speeds

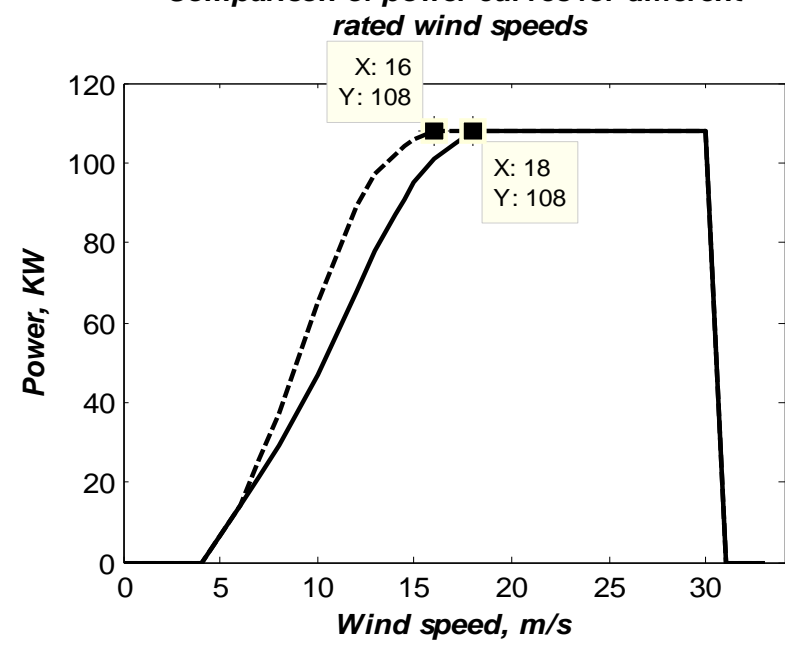

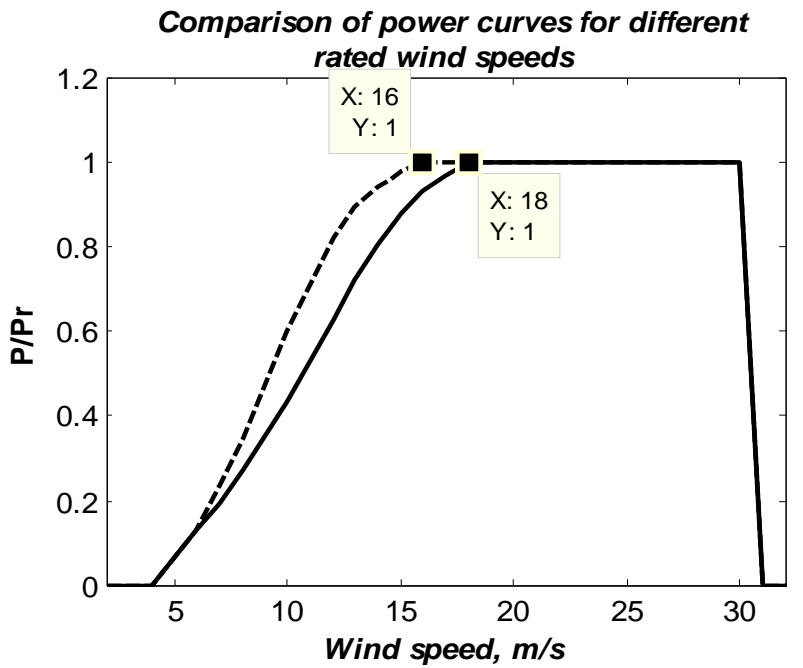

Figs 4: Comparison of power curves for different rated wind speed

Owing to engineering and economic reasons, the cut-out speed normally does not exceed $2 \mathrm{Vr}$ in most of the commercial designs [21]. This indicates that Vout is influenced by Vr. For a given rotor area and efficiency, the rated speed is directly correlated with the system's rated power. The effect of $\mathrm{Vr}$ on the capacity factor is shown in Figure 3 (c), the capacity factor decreases with increase in Vr. Consequently, selecting a wind turbine takes into account its speeds characteristics in consideration to have a useful pairing performance index. The reason is obvious from Figures. 4, in which the power curves of two similar systems, which differ only in the rated velocity, are compared. With the increase in $\mathrm{Vr}$, area under the power curve reduces, which is finally reflected as the reduction in the capacity factor and the output energy. However, for the same rated power, lower rated velocity will in turn demand a bigger rotor for the turbine. As the rated power is proportional to the rotor area and rated speed, this will increase the unit cost of energy produced. For a given rotor size, increase in the rated velocity means increase in the rated power and thus the generator size. If this higher rated velocity is justified by the strength and nature of the prevailing wind regime, this would in turn improve the energy production and thus reduce the cost of unit energy generated. At the same time, if the rated wind speed is too high for the regime, the system will not operate any more with its rated capacity. May be about twice the average wind speed for regimes with $\mathrm{k}=2$. In trade winds with higher $\mathrm{k}, \mathrm{Vr}$ may be 1.3 times of the average wind speed [21]. The turbine performance models discussed here can be used to choose the turbine which is most suited for a given wind regime. The above discussions are hypothetical and meant only to demonstrate the effect of $\mathrm{Vc}, \mathrm{Vr}$ and Vout on the turbine performance. Unless under special situations, it is not practical to design wind turbines for a specific site, because economically it is not feasible. Let us, analyze this problem in a more practical point of view. There is several wind turbines of the same power class but with deferent power curves performance available in the market. Designer of the wind energy project often chooses a system from these available options for his site. Selection of the right machine for the right site plays a capital role in the success of the project. Depending on the Weibull scale and shape parameters, it is possible to identify the rated speed suitable for a particular wind regime [ 4 $5,13]$. Selecting the appropriate machine to a given site leads to 
identify its speeds characteristic. The identification of $\mathrm{Vc}, \mathrm{Vr}$ and Vout is made by plotting the capacity factor curves. Capacity factor versus cut-in speed at constant rated speeds and versus rated speed at constant cut-in speeds. Instead of calculating the capacity factor of each wind turbine among a large number of wind turbines for the chosen site or a large number of sites and turbines, this can be very tedious and time consuming. This methodology helps to locate the maximum and the minimum of the pairing performance index corresponding to cut-in speed range $V c_{\text {Min }} \leq V c \leq V c_{\text {Max }}$ and rated speed range $V r_{\text {Min }} \leq V r \leq V r_{\text {Max }}$. In the preceding paragraphs, we showed that the capacity factor depends on five variables, i.e., the two parameters of Weibull distribution function that indirectly involve the wind energy potential of the sites and the speeds characteristic of wind turbine; $\mathrm{k}, \mathrm{C}, \mathrm{Vc}, \mathrm{Vr}$ and Vout, therefore, the optimization between site and wind turbine conducts to select the adequate wind energy conversion system among existing ones at the market, in order to optimize the expected energy output, this leads to an optimal CF. This methodology is applied to four Algerian sites. Table 1 summarizes the yearly mean parameters of Weibull probability distribution function and the yearly mean wind speed (Vm), mean cubic wind speed $(\mathrm{V} 3 \mathrm{~m})$ and average power density (PD). The data were collected by Algerian Meteorological Department at a standard height of $10 \mathrm{~m}$, where evaluated as yearly mean value over an entire period of 10 years. The sites are aggregated in two geographic regions, (A02) high plateau region and (A01), (A02), (A03) Sahara region.

Table 1: Wind Data of the sites at an altitude $10 \mathrm{~m}$

\begin{tabular}{|l|l|l|l|c|c|c|c|}
\hline Sites & Symbol & $\begin{array}{l}\mathbf{R} \\
\mathbf{m}\end{array}$ & $\mathbf{k}$ & $\begin{array}{c}\mathbf{C} \\
\mathbf{m} / \mathbf{s}\end{array}$ & $\begin{array}{c}\mathbf{V m} \\
\mathbf{m} / \mathbf{s}\end{array}$ & $\begin{array}{c}\mathbf{V 3 m} \\
\mathbf{m} / \mathbf{s}\end{array}$ & $\begin{array}{c}\mathbf{P D} \\
\mathbf{W} / \mathbf{m}^{2}\end{array}$ \\
\hline Adrar & $\mathrm{A} 01$ & 0.01 & 2.15 & 7.20 & 6.37 & 7.73 & 283.11 \\
\hline Tiaret & $\mathrm{A} 02$ & 0.02 & 1.58 & 6.90 & 6.19 & 8.43 & 367.27 \\
\hline In Salah & $\mathrm{A} 03$ & 0.02 & 1.78 & 6.01 & 5.42 & 6.92 & 203.01 \\
\hline Ghardaïa & A04 & 0.03 & 1.65 & 5.60 & 5.00 & 6.68 & 183.12 \\
\hline
\end{tabular}

The Vertical extrapolation of the wind data at an elevation more than $10 \mathrm{~m}$ listed in table 2 is computed with the help of Eqs. (12), (13) and (14). [22, 24, 25]:

$$
\begin{gathered}
C=C_{1}\left(\frac{H}{H o}\right)^{m} \\
m=\left(\ln \left(\frac{Z_{g}}{R}\right)\right)^{-1}+\frac{0.0881 \ln \left(C_{1}\right)}{1-0.00881 \ln (0.1 H o)} \\
k=k_{1}\left(\frac{H}{H o}\right)\left[\left(1-0.0881 \ln \left(\frac{H}{H o}\right)\right)^{-1}\right]
\end{gathered}
$$

Where, $\mathrm{k}_{1}, \mathrm{C}_{1}$ are the shape and scale parameters at standardized height $\mathrm{Ho}$ of $10 \mathrm{~m}, \mathrm{Zg}$ is the geometric average between heights hub, $\mathrm{R}$ is the roughness surface and is a terrain-dependent parameter.

\section{RESULTS AND DISCUSSION}

All of the results are integral quantities calculated over an entire number of years, and the energy terms are yearly averages. Table 2 collects the main wind data for representative sites of the two regions of Algeria. In this table, the yearly mean velocity at a height of $24 \mathrm{~m}$, and the available wind power density $\left(\mathrm{W} / \mathrm{m}^{2}\right)$ computed directly by the wind data are presented. It can be seen that the yearly mean wind speeds in the locations could reach as high as 7.18, 7.20, 6.20 and 5.73 $\mathrm{m} / \mathrm{s}$ in regions (A01), (A02), (A03) and (A04) respectively.

\begin{tabular}{|c|c|c|c|c|c|c|c|}
\hline $\begin{array}{l}\text { Site } \\
\mathbf{s}\end{array}$ & $\begin{array}{l}\text { H } \\
\mathbf{m}\end{array}$ & $\mathbf{k}$ & $\underset{\mathbf{m} / \mathbf{s}}{\mathbf{C}}$ & $\begin{array}{l}\mathrm{Vm} \\
\mathrm{m} / \mathrm{s}\end{array}$ & $\begin{array}{l}\text { V3m } \\
\mathrm{m} / \mathrm{s}\end{array}$ & $\underset{W / \mathbf{m}^{2}}{\mathbf{P D}}$ & $\begin{array}{l}\text { ED } \\
\text { MWh } \\
/ \mathbf{m}^{2} \\
/ \text { year }\end{array}$ \\
\hline A01 & 24 & 2.33 & 8.11 & 7.18 & 8.51 & 378.36 & 3.31 \\
\hline A02 & 24 & 1.71 & 7.87 & 7.20 & 9.23 & 481.92 & 4.22 \\
\hline A03 & 24 & 2.17 & 7.02 & 6.20 & 7.51 & 260.23 & 2.28 \\
\hline A04 & 24 & 1.78 & 6.44 & 5.73 & 7.41 & 249.78 & 2.19 \\
\hline
\end{tabular}

Table 2: Computed Weibull scale and shape parameters and Mean velocities at $24 \mathrm{~m}$ elevation

Figures 5 display the capacity factor curves versus cut-in speed at constant rated speeds and the capacity factor curves versus rated speed at constant cut-in speeds for each site, which is contained in all other quantities, depends only on kinematic parameters, concentrated mainly on the effect of $\mathrm{Vc}$ and $\mathrm{Vr}$ because the cut-out speeds of wind turbines is higher than 20 $\mathrm{m} / \mathrm{s}$, its effect is very weak ( see Figure.3(b)), otherwise, the results of the matching of the wind energy conversion system with the wind distribution for the expected high-potential wind generation sites in the four sites.

Figures 5 charts (a) - (h) show the capacity factor range, i.e., the best pairing performance index is located between the CFmin and CFmax and their corresponding specification speeds range of the machines, which could be selected to install in sites in order to optimize the generated energy. These figures show the variation of capacity factor at various cut-in speed at constant rated speeds and different rated speeds at constant cutin speed evaluated with the parameters of Weibull distribution function of each site, the best performance indices CFmax were obtained at low values of cut-in and rated speed, the acceptable CFmin high than 0.25 result from high values of cut-in and rated speed.

Capacity factor versus cut-in speed at constant rated speeds Site A01

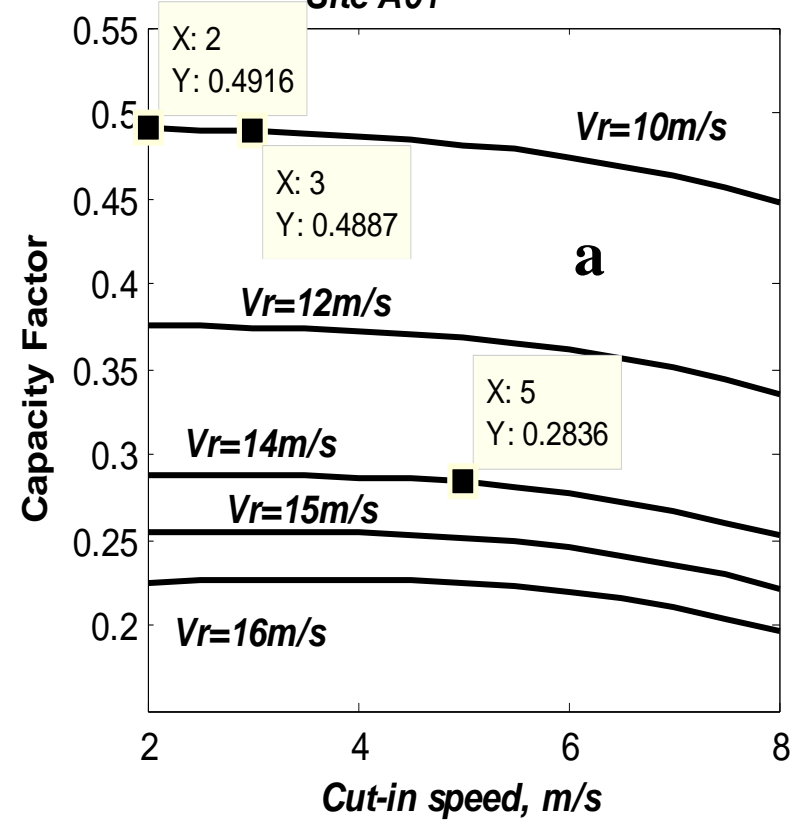




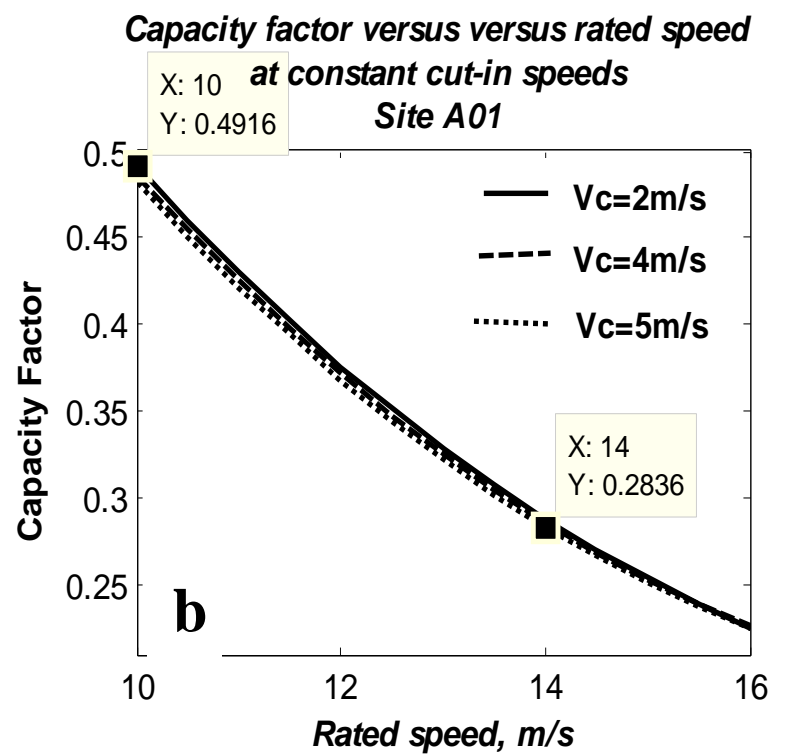

Capacity factor versus cut-in speed at constant rated speeds

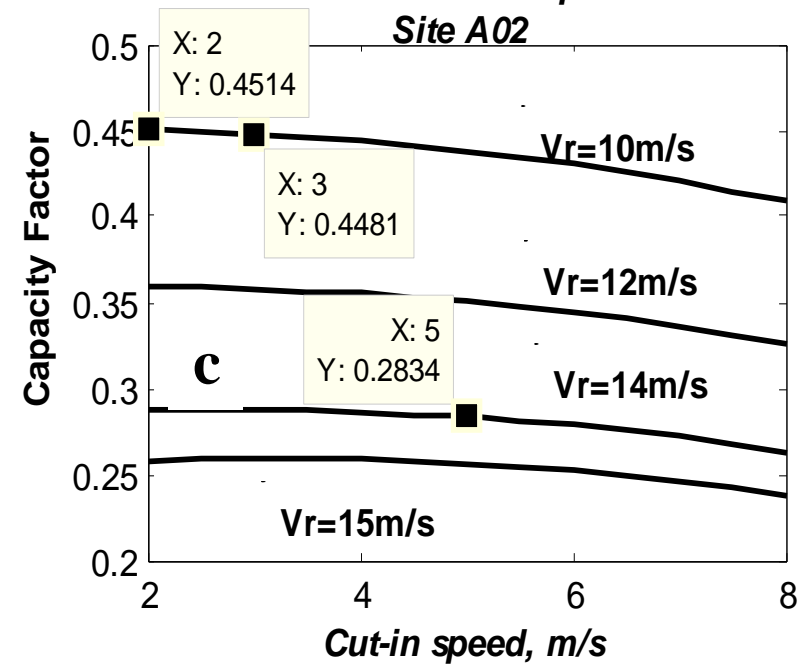

Capacity factor versus rated speed

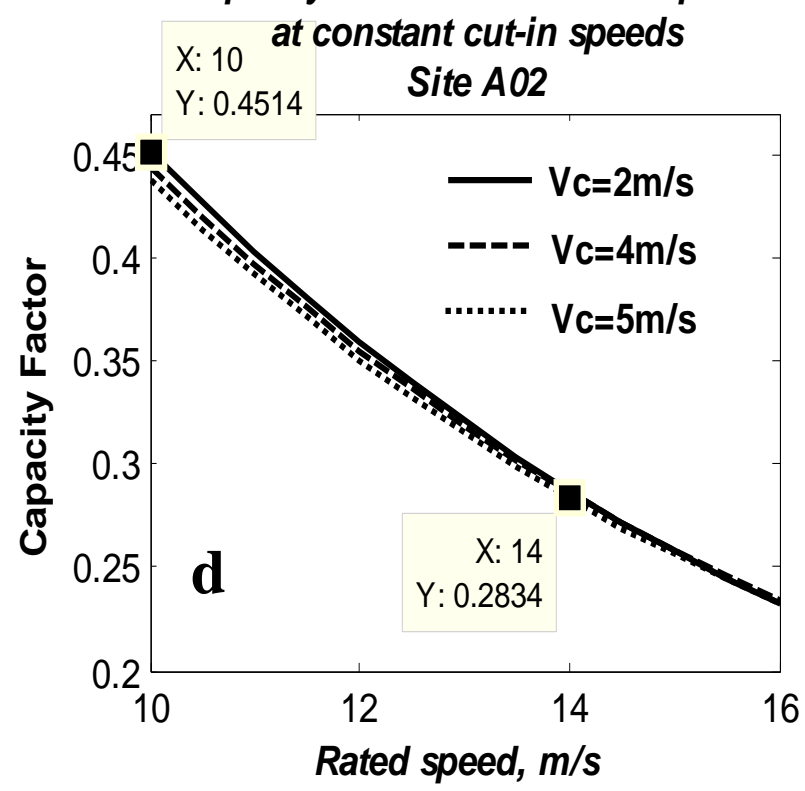

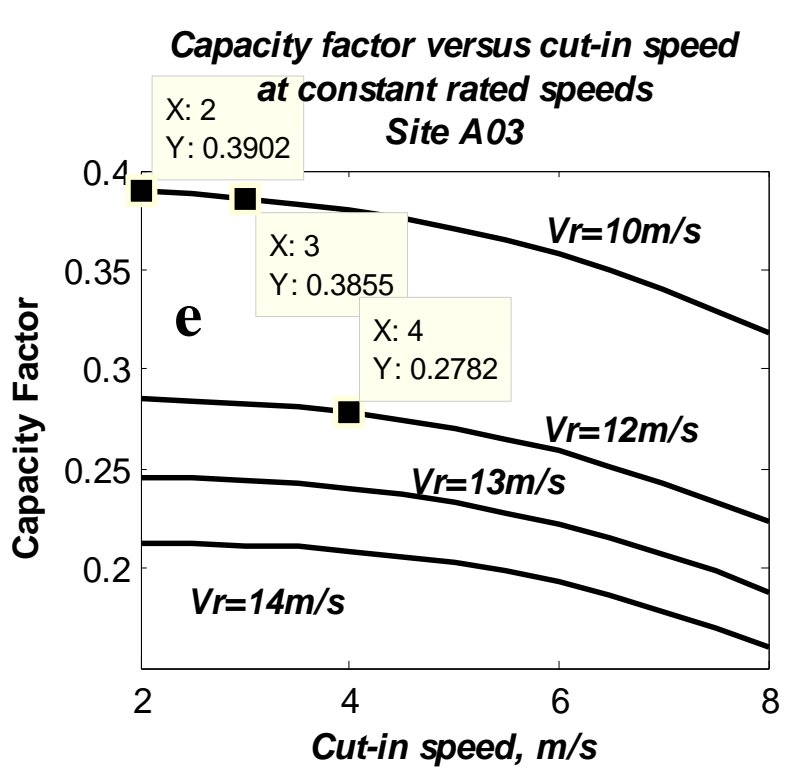
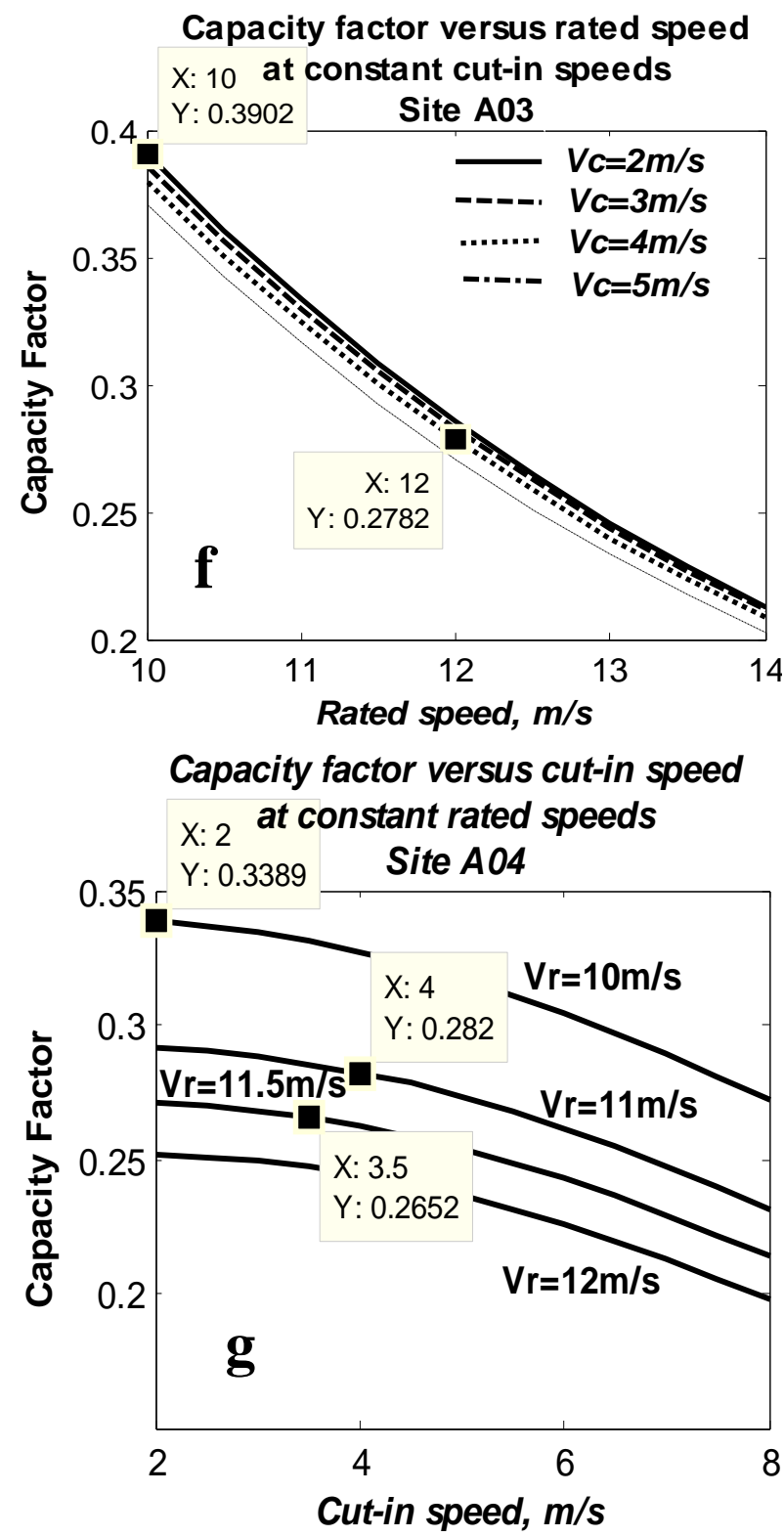


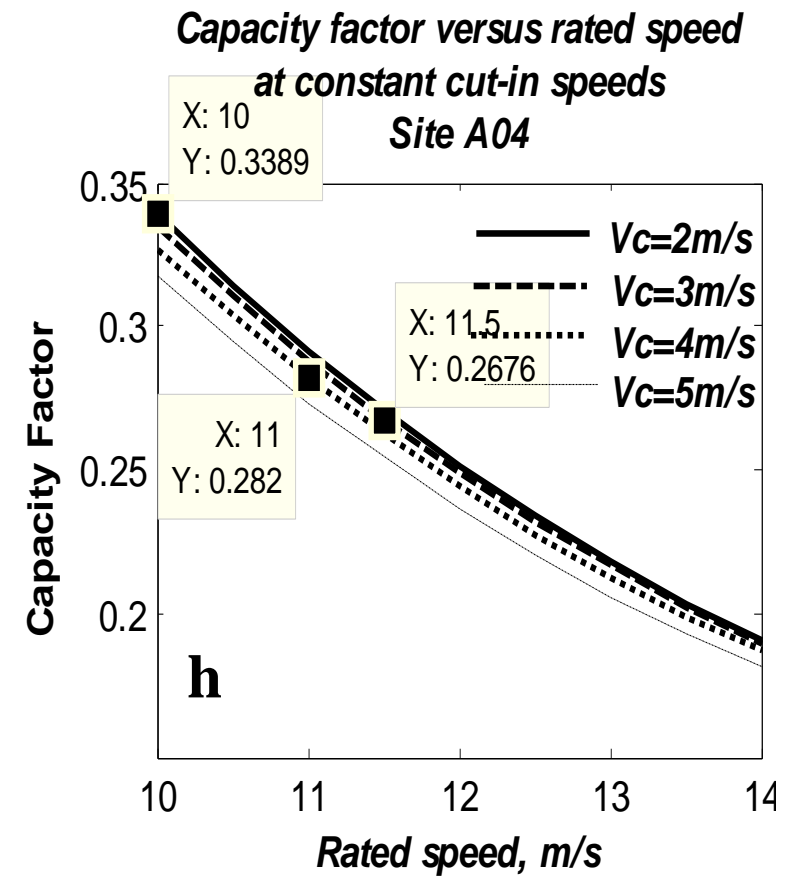

Figs 5: Capacity factor versus cut-in speed at constant rated speed and Capacity factor versus rated speed at constant cut-in speed

The cut-in and rated speed range results of wind turbine can be chosen to be installed at a desired site, which were extracted from the curves of capacity factor sketched on Figs.5. These best results are summarized in table 3 .

Table 3. Specific speeds range of suitable machines.

\begin{tabular}{|l|l|l|l|l|l|}
\hline Sites & & $\mathbf{A 0 1}$ & $\mathbf{A 0 2}$ & $\mathbf{A 0 3}$ & $\mathbf{A 0 4}$ \\
\hline \multirow{2}{*}{$\begin{array}{l}\text { Specifically } \\
\text { speeds }\end{array}$} & Vc m/s & $2-5$ & $2-5$ & $2-5$ & $2-4$ \\
\cline { 2 - 6 } & Vr m/s & $9-14$ & $9-14$ & $9-12$ & $9-11.5$ \\
\hline \multirow{2}{*}{$\begin{array}{l}\text { Capacity } \\
\text { factor }\end{array}$} & CFmin & 0.280 & 0.280 & 0.278 & 0.288 \\
\cline { 2 - 6 } & CFmax & 0.450 & 0.450 & 0.390 & 0.339 \\
\hline
\end{tabular}

Now, we can easily to choose the favorable wind turbines using the range of speeds mentioned in table 3, which perform suitably with the considered sites among the twenty four models of wind turbine generators commercially available in market, which are listed in table 4 . The wind turbines models represent different ranges of characteristic speeds and rated powers. In addition, they have different fields of application. Some models are small size wind turbines, suitable for low energy needs (water pumping and/or electric supply) in remote areas, although their design, performance and environmental needs are quite different and medium size models, however, is suitable for small electric networks or for grid connection.
Table 4: Technical specification of the twenty-four Wind Energy Conversion system models

\begin{tabular}{|l|l|l|l|}
\hline Wind turbines models & $\begin{array}{l}\text { Number } \\
\text { of } \\
\text { blades }\end{array}$ & $\begin{array}{l}\text { Height } \\
\text { Hub h } \\
\text { (m) }\end{array}$ & $\begin{array}{c}\text { D } \\
(\mathbf{m})\end{array}$ \\
\hline Proven wt6000 & 3 & $10-24$ & 5.6 \\
\hline Raum energy 3.5/2 & 3 & 15 & 22.0 \\
\hline Bergy & 3 & 24 & 7.0 \\
\hline Tma10 & 3 & 5.5 & 6.0 \\
\hline Repower & 3 & 24 & 13.0 \\
\hline Gaia11 & 3 & 24 & 13.0 \\
\hline Jacobs 20kw & 3 & 24 & 9.5 \\
\hline Fuhrländer fl 30 lm 6.1 & 3 & $18-27$ & 12.8 \\
\hline Epg35 & 3 & 24 & 19.8 \\
\hline Ew50 & 3 & 24 & 15.0 \\
\hline Bwcxl.50 & 3 & 24 & 14.0 \\
\hline Epge50 & 3 & 24 & 19.2 \\
\hline Nordtank65sac.dsm6.12.0 & 3 & 24 & 16.5 \\
\hline Vestas v17- 65 kw & 3 & $24-30$ & 15.0 \\
\hline Vestas v17-75 kw & 3 & 23 & 17.0 \\
\hline Wes18 mk1 80 kw & 2 & $30-40$ & 18.0 \\
\hline Fl100 & 3 & 35 & 21.0 \\
\hline Ades wind turbine 100 & 1 & 24 & 28.0 \\
\hline Nordtank 130f 20.5 & 3 & 26 & 20.5 \\
\hline Micon 108 & 3 & 24 & 18.9 \\
\hline Bonus150 & 3 & 24 & 24.5 \\
\hline Nordtank150sac.dsm4.20.07 & 3 & $24-48.8$ & 25.0 \\
\hline Norwin n150 & 3 & 24 & 25.4 \\
\hline Fgw (rank tacke) tw150 & 3 & 24 & 20.5 \\
\hline & & & \\
\hline
\end{tabular}

\begin{tabular}{|l|l|l|l|l|}
\hline wind turbines models & $\begin{array}{l}\mathbf{P r} \\
(\mathbf{k w})\end{array}$ & $\begin{array}{l}\mathbf{V c} \\
\mathbf{m} / \mathbf{s}\end{array}$ & $\begin{array}{l}\mathbf{V r} \\
\mathbf{m} / \mathbf{s}\end{array}$ & $\begin{array}{l}\text { Vout } \\
\mathbf{m} / \mathbf{s}\end{array}$ \\
\hline Proven wt6000 & 6.0 & 2.5 & 10.0 & 30 \\
\hline Raum energy 3.5/2 & 3.5 & 2.8 & 11.0 & 22 \\
\hline Bergy & 6.0 & 4.0 & 11.7 & 25 \\
\hline Tma10 & 11.0 & 2.24 & 15.2 & 25 \\
\hline Repower & 11.0 & 3.0 & 9.5 & 25 \\
\hline Gaia11 & 14.8 & 3.5 & 12.0 & 25 \\
\hline Jacobs 20kw & 20.0 & 2.24 & 11.6 & 25 \\
\hline Fuhrländer fl 30 lm 6.1 & 30.0 & 3.0 & 12.0 & 25 \\
\hline Epg35 & 35.0 & 3.0 & 10.0 & 25 \\
\hline Ew50 & 50.0 & 4.0 & 11.3 & 22 \\
\hline Bwcxl.50 & 50.0 & 2.5 & 11.0 & 30 \\
\hline Epge50 & 50.0 & 3.0 & 11.0 & 25 \\
\hline Nordtank65sac.dsm6.12.0 & 65.0 & 3.6 & 15.0 & 25 \\
\hline Vestas v17- 65 kw & 65.0 & 4.0 & 14.0 & 25 \\
\hline Vestas v17-75 kw & 75.0 & 3.5 & 15.0 & 25 \\
\hline Wes18 mk1 80 kw & 80.0 & 3.0 & 12.5 & 25 \\
\hline Fl100 & 100 & 3.0 & 12.0 & 25 \\
\hline Ades wind turbine 100 & 100 & 4.0 & 9.0 & 20 \\
\hline Nordtank 130f 20.5 & 130 & 3.7 & 13.0 & 25 \\
\hline Micon 108 & 108 & 3.5 & 15.0 & 27 \\
\hline Bonus150 & 150 & 4.0 & 12.0 & 25 \\
\hline Nordtank150sac.dsm4.20.07 & 150 & 4.0 & 12.0 & 25 \\
\hline Norwin n150 & 150 & 4.0 & 12.3 & 25 \\
\hline Fgw (rank tacke) tw150 & 150 & 4.0 & 14.0 & 24 \\
\hline & & & \\
\hline
\end{tabular}


The winds turbines can be paired with the sites according to the results listed in table 3, which will be selected among the wind turbines enumerated in table 4 . The opted wind machines are recapitulated in the following table 5.This table contains the capacity factor computed with the chosen wind turbines and the yearly average expected energy, which could be generated by the selected wind turbines.

Table 5. Selected wind Energy Conversion systems.

\begin{tabular}{|c|c|c|c|c|c|c|}
\hline Sites & $\begin{array}{l}\text { Wind } \\
\text { turbines } \\
\text { models }\end{array}$ & $\begin{array}{l}\text { Pr } \\
\text { kw }\end{array}$ & $\begin{array}{l}\mathrm{Vc} \\
\mathrm{m} / \mathrm{s}\end{array}$ & $\begin{array}{l}\mathrm{Vr} \\
\mathrm{m} / \mathrm{s}\end{array}$ & $\mathbf{C F}$ & $\begin{array}{c}\mathbf{E} \\
\text { MWh } \\
\text { /year }\end{array}$ \\
\hline \multirow{10}{*}{ A01 } & Ew50 & 50 & 4.0 & 11.3 & 0.4088 & 179.05 \\
\hline & Bwcxl & 50 & 2.5 & 11 & 0.4295 & 188.13 \\
\hline & Pge50 & 50 & 3.0 & 11 & 0.4284 & 187.62 \\
\hline & vestas v17 & 65 & 4.0 & 14 & 0.2860 & 162.85 \\
\hline & Fl100 & 100 & 3.0 & 12 & 0.3741 & 327.70 \\
\hline & Ades 100 & 100 & 4.0 & 9 & 0.5542 & 485.48 \\
\hline & Nordtank & 130 & 3.7 & 13 & 0.3260 & 428.42 \\
\hline & Nonus & 150 & 4.0 & 12 & 0.3719 & 485.48 \\
\hline & Nordtank & 150 & 4.0 & 12 & 0.3719 & 488.65 \\
\hline & Norwin & 150 & 4.0 & 12 & 0.3572 & 469.32 \\
\hline \multirow{11}{*}{ A02 } & Fgw tw & 150 & 4.0 & 14 & 0.2860 & 375.80 \\
\hline & Ew50 & 50 & 4.0 & 11.3 & 0.3812 & 166.98 \\
\hline & Bwcxl & 50 & 2.5 & 11 & 0.4009 & 175.59 \\
\hline & Pge50 & 50 & 3.0 & 11 & 0.3996 & 175.02 \\
\hline & Vestas 17 & 65 & 4.0 & 14 & 0.2854 & 162.53 \\
\hline & Fl100 & 100 & 3.0 & 12 & 0.3570 & 312.71 \\
\hline & Ades 100 & 100 & 4.0 & 9 & 0.4952 & 433.79 \\
\hline & Nordtank & 130 & 3.7 & 13 & 0.3169 & 416.39 \\
\hline & Bonus150 & 150 & 4.0 & 12 & 0.3543 & 465.56 \\
\hline & Nordtank & 150 & 4.0 & 12 & 0.3543 & 465.56 \\
\hline & Norwin & 150 & 4.0 & 12 & 0.3428 & 450.38 \\
\hline \multirow{8}{*}{ A03 } & Fgw & 150 & 4.0 & 14 & 0.2841 & 373.37 \\
\hline & Ew50 & 50 & 4.0 & 11.3 & 0.3096 & 135.63 \\
\hline & Bwcxl & 50 & 2.5 & 11 & 0.3318 & 145.32 \\
\hline & Pge50 & 50 & 3.0 & 11 & 0.3298 & 144.44 \\
\hline & Fl100 & 100 & 3.0 & 12 & 0.2827 & 247.67 \\
\hline & Ades 100 & 100 & 4.0 & 9.0 & 0.4437 & 388.71 \\
\hline & Nordtank & 150 & 4.0 & 12 & 0.2782 & 365.50 \\
\hline & Norwin & 150 & 4.0 & 12.3 & 0.2659 & 349.38 \\
\hline \multirow{4}{*}{ A04 } & Ades 100 & 100 & 4.0 & 9.0 & 0.3795 & 166.22 \\
\hline & Ew50 & 50 & 4.0 & 11.3 & 0.2698 & 118.19 \\
\hline & Bwcxl.50 & 50 & 2.5 & 11 & 0.2900 & 127.01 \\
\hline & Pge50 & 50 & 3.0 & 11 & 0.2879 & 126.10 \\
\hline
\end{tabular}

Optimum siting of wind turbine generators is investigated from the viewpoint of site and wind turbine generator selection. The methodology of analysis is based on the computation of annual capacity factors at the study sites. Capacity factors are obtained using Weibull statistical model and the selected wind turbines. Inspecting the results collected in table 5, we can observe the adopted wind turbines perform suitably with the sites, which are chosen using the speeds range determined with the help of the methodology described in the previous section. The computed values of capacity factor were determined with the specific speeds of the selected wind turbines and the parameters of the Weibull distribution function characterizing the wind potential of the sites, these values show all the chosen wind turbines match well with the sites A01, A02, A03 and A04.

Examining carefully the capacity factor values, we lead to the following remark, a high value often does not indicate that the selected wind turbine is the one which pairs perfectly with such site in viewpoint of energy output although it is matched with the selected site for example the highest values are obtained by
ADES100 wind turbine at the sites A01 and A02, which are 0.5542 and 0.4952 respectively but its produced energy is less than the energy output generated with the wind turbine NORDTANK150 although its capacity factor at the sites A01 and $\mathrm{A} 02$ is 0.3719 and 0.3543 respectively, these difference of energy is due to the rated power, where the rated power is related to the rotor swept area and the rated efficiency of the wind energy conversion system, hence for to choose a turbine of wind among those which were selected, the choice is based on the energy output and if some wind energy conversion system have a same technical specification the choice is made on the basis of the cost of the system.

Some wind turbines are not selected because their specific speeds belong out to the speeds range of the benefit wind turbines. We can see the wind turbines models MICON 108 and NORDTANK65 are not chosen for their high rated speeds for all locations, the capacity factor values obtained with these wind turbines at sites A01, A02 and A03 are 0.2581, 0.2534 and 0.1848 respectively. These machines provide the same values of capacity at the same site because they have the same rated speeds and their cut-in speeds are pretty similar, but of different rated power, therefore different energy output.

Another note concerning the performance of different turbines at same site, if a turbine has higher $(\mathrm{Vc} / \mathrm{Vr})$ ratios than other turbines, then it gives higher capacity factor. Let us take as example the site A01or other site of table 5, the highest capacity factor is obtained with ADES100 because possess a high speeds ratio than the other wind turbines, which is 0.4444 .

\section{CONCLUSION}

The methodology presented in this paper, to perform the planning and development stages of installation of wind power stations will enable the wind power developer or the power utilities to make a judicious and rapid without wasting times of the choice of wind turbine generators systems from the available potential sites. This methodology is based on the capacity factor curves evaluated at different cut-in speeds Vc and constant rated speed $\mathrm{Vr}$ and Weibull distribution function, in order to determine the speeds range of cut-in speed $\mathrm{Vc}$ and rated speed Vr. Which leads to better pairing indices performance between wind turbines and sites and to select the wind turbines can be installed among the existing ones, this methodology is easy and allows saving time and reducing the conditions specified. This methodology is used to select the benefits wind turbines can be to set up in four different Algerian sites. In the end, we summarize from the results listed in table 5, the choice of wind turbines is based on the average yearly energy output, which can provide. Hence, the final choice will be founded on the marketing cost of its wind turbines and the installation cost. 
Table 6: Profitable wind turbines

\begin{tabular}{|c|l|c|c|c|c|l|}
\hline \multirow{3}{*}{ Sites } & $\begin{array}{l}\text { wind } \\
\text { turbines } \\
\text { models }\end{array}$ & $\begin{array}{c}\mathbf{P r} \\
\mathbf{k w}\end{array}$ & $\begin{array}{c}\mathbf{V c} \\
\mathbf{m} / \mathbf{s}\end{array}$ & $\begin{array}{c}\mathbf{V r} \\
\mathbf{m} / \mathbf{s}\end{array}$ & $\mathbf{C F}$ & $\begin{array}{l}\mathbf{E} \\
\mathbf{M W h} \\
\mathbf{y e a r}\end{array}$ \\
\hline \multirow{4}{*}{ A01 } & Ades 100 & 100 & 4.0 & 9 & 0.554 & 485.48 \\
\cline { 2 - 7 } & Bonus150 & 150 & 4.0 & 12 & 0.372 & 485.48 \\
\cline { 2 - 7 } & Nordtank150 & 150 & 4.0 & 12 & 0.372 & 488.65 \\
\cline { 2 - 7 } & Norwin 150 & 150 & 4.0 & 12 & 0.357 & 469.32 \\
\hline \multirow{4}{*}{ A02 } & Fgw Tw150 & 150 & 4.0 & 14 & 0.286 & 375.80 \\
\cline { 2 - 7 } & Bonus150 & 150 & 4.0 & 12 & 0.354 & 465.56 \\
\cline { 2 - 7 } & Nordtank150 & 150 & 4.0 & 12 & 0.354 & 465.56 \\
\cline { 2 - 7 } & Norwin 150 & 150 & 4.0 & 12 & 0.343 & 450.38 \\
\hline \multirow{3}{*}{ 003 } & Fgw & 150 & 4.0 & 14 & 0.284 & 373.37 \\
\cline { 2 - 7 } & Ades 100 & 100 & 4.0 & 9 & 0.443 & 388.71 \\
\cline { 2 - 7 } & Nordtank150 & 150 & 4.0 & 12 & 0.278 & 365.50 \\
\cline { 2 - 7 } & Norwin 150 & 150 & 4.0 & 12.3 & 0.266 & 349.38 \\
\hline \multirow{2}{*}{ A04 } & Ades 100 & 100 & 4.0 & 9.0 & 0.379 & 166.22 \\
\cline { 2 - 7 } & Bwcxl.50 & 50 & 2.5 & 11 & 0.290 & 127.01 \\
\hline
\end{tabular}

\section{REFERENCE}

[1] C. G. Justus: Nationwide assessment of potential power output from aero-generators. in Proc. 2nd U.S Nat. Conf. Wind Engineering Research, Ft. Collins, CO, Jun. 22-25, 1975 .

[2] J. P. Hennessey, Jr: Some aspects of wind power statistics and performance analysis of a $6 \mathrm{MWwind}$ turbine-generator. J. Appl. Meteorol., vol. 16, no. 2, pp. 119-28, Feb. 1997.

[3] R. B. Corotis: Stochastic Modeling of Site Wind Characteristics. ERDA Rep. RLO/2342-77/2, Sep. 1977.

[4] R. B. Corotis, A. B. Sigl, and J. Klein: Probability modeling of wind velocity magnitude and persistence.Sol. Energy, vol. 20, no. 6, pp. 483-93, 1978.

[5] Rosen KR, Van Buskirk R, Garbesi K: Wind energy potential of coastal Eritrea: an analysis of sparse wind data. Solar Energy 1999; 66 (3):201-13.

[6] Li G: Feasibility of large scale offshore wind power for Hong Kong a preliminary study. Renewable Energy, 21; 2000; pp 387- 402.

[7] $\mathrm{Lu} \mathrm{L}$, Yang $\mathrm{H}$, Burnett J: Investigation on wind power potential on Hong Kong an analysis of wind power and wind turbine characteristics. Renewable Energy 27; 2002; pp 1-12.

[8] Mathew S, Pandey KP, Kumar A: Analysis of wind regimes for energy estimation. Renewable Energy 25: 2002; pp 81-99.

[9] Corotis RB, Sigl AB, Klein J: Probability models of wind velocity magnitude and persistence. Solar Energy 1978; 20:483-93.

[10] Rehman S, Halawani TO, Husain T: Weibull parameters for wind speed distribution in Saudi Arabia. Solar Energy 1994; 53(6):473-9.

[11] Beyer HG, Nottebaum K: Synthesis of long-term hourly wind speed time series on the basis of European Wind Atlas data. Solar Energy 1995; 54(5):351-5.
[12] Lun IYF, Lam JC: A study of Weibull parameters using long-term wind observations. Renewable Energy 2000; 20:145-53.

[13] Tsang-Jung Chang, Yu-Ting Wu, Hua-Yi Hsu, ChiaRen Chu, Chun-Min Liao: Assessment of wind characteristics and wind turbine characteristics in Taiwan. Renewable Energy 28 (2003) 851-871

[14] Pallabazzer R: Evaluation of wind-generator potentiality. Sol Energy, 1995; 55:49-59.

[15] Stevens MJM, Smulders PT: The estimation of the parameters of the Weibull wind speed distribution for wind energy utilization purpose. Wind Eng 1979; 3(2):132-45.

[16] Akpinar, EK, Akpinar, S: An assessment on seasonal analysis of wind energy characteristics and wind turbine characteristics. Energy Conversion and Management 46, 1848-67 (2005)

[17] N.Vaughn: Renewable Energy and the Environment Press, Ed. 2009 pp $63-101$

[18] Gary L. Johnson: Wind energy systems. Electronic Edition Manhattan, October 10, 2006, pp. 61-70-157

[19] O.A. Jaramillo, M.A. Borja: Wind speed analysis in La Ventosa Mexico a bimodal probability distribution case. Renewable Energy 29 (2004), Elsevier, pp. 1624-1628

[20] Balouktsis, A, Chassapis, D, Karapantsios, TD: A nomogram method for estimating the energy produced by wind turbine generators. Solar Energy $72,251-259$ (2002)

[21] Mathew Sathyajith et al. Wind Energy: Fundamentals, Resource Analysis and Economics. Springer-Verlag Berlin Heidelberg 2006; 169-170

[22] Justus C.G., Mikhail W.R: Height variation of wind Speed and wind distributions statistics. Geophysical Research Letters. 1976. Vol. 3, No 5. P. 261-264

[23] Tenneekes A.: The logarithmic wind profile. J. of Atmospheric sciences, vol. 30, pp. 234:238, 1973.

[24] Mikhail A.S:Height Extrapolation of Wind Data. ASME, vol. 107, pp. 10- 14, 1985.

[25] Poje S., B. Cividini: Assessment of Wind Energy Potential in Croatia. Solar Energy, Vol.41 N ${ }^{\circ}$ pp 543 $554,1988$.

\section{Authors' information}

Mohamed Bencherif is Dr in energy physics and materials and a member in Renewable energy laboratory, Department of physics, University of Tlemcen, Algeria, B. Nabil Brahmi is lecturer and teacher of theoretical physics in physics department and is an assistant at renewable energies laboratory and theoretical physics laboratory, University of Tlemcen, Algeria. Abdelhak Chikhaoui is lecturer and a teacher in physics department and is at the head of the renewable energies laboratory, University of Tlemcen, Algeria, 